\title{
The adaptive moral challenge of COVID-19
}

\author{
Lindsay J. Thompson ${ }^{1}$
}

Received: 11 July 2020 / Accepted: 27 November 2020 / Published online: 8 February 2021

(c) The Author(s), under exclusive licence to Springer-Verlag GmbH, DE part of Springer Nature 2021

\begin{abstract}
This author offers of narrative of hope in response to the coronavirus pandemic by viewing it as a wake-up call to lean into the adaptive moral challenge of stewardship for the future of humanity and the planet. Acknowledging the many material and social benefits of a global regime of free market urbanism built on advances in science and technology, this is a point in geohistory, the Anthropocene, when the impact of human activities on the Earth has begun to outcompete natural processes. The coronavirus has illuminated systemic moral failures and new moral challenges of the Anthropocene that call for adaptive response if we are to build a hopeful future for humanity and the planet. Pointing to millennia of human adaptive response to threats and disasters, the author asserts an evolutionary hardiness attributable as much to moral capacities as rational intelligence as a singularly defining trait fueling millennia of human adaptive learning and thrival. The current pandemic is the latest point in humanity's moral evolution of adaptive response to moments of urgent threat that have tested, expanded, and defined our character and moral capacities as a species. Rather than falter under the moral burden of the coronavirus threat and its consequences, the author views this pivotal point as an opportunity to stretch human moral horizons by taking responsibility for the urgent moral challenges we have created and inventing new ethical frameworks and tools that will lead us to new moral understandings and solutions to the moral challenges we face.
\end{abstract}

Keywords COVID-19 $\cdot$ Adaptive moral challenge $\cdot$ Moral resilience $\cdot$ Anthropocene

\section{Introduction}

Humans are a species that thrives on disaster. Beneath the patina of our carefully curated lives, we are all animals with primal instincts easily activated by risk and threat. The fact that we exist and flourish by constructing and managing complex societies with built environments, material comforts, and virtual realities to occupy

Lindsay J. Thompson

lthompson@jhu.edu

1 Johns Hopkins Carey Business School, Baltimore, MD 21202, USA 
our time and talents attests to cognitive and noetic capacities honed by millennia of adaptive learning in response to relentless, ubiquitous threats to our survival. For much of the last generation, however, threats of terrorism, war, cybersecurity, political unrest, and poverty have shifted attention away from the natural fragility of humanity in the biosphere. Free market enthusiasts have embraced a global regime of financialized urban human flourishing as a "triumph" that Harvard urban economist Edward Glaeser claims is making people "richer, smarter, greener, healthier, and happier," with barely a nod to the foundation of science and technology on which the safety of urban density, connection rest or the grim realities of overcrowding, crumbling infrastructure, tenuous land tenure, porous safety net, and social inequalities that make cities unlivable for most of the world's urban poor (Glaeser 2011; Singer 2004). As Glaeser recently acknowledged, before the invention of vaccines and public health infrastructure, the dense connections of cities were deadly vectors of disease from the Athenian plague in 430 BCE to the 1918 Spanish Flu (Glaeser 2020).

And here we are, facing another pandemic threat. What will we learn from it and how will we adapt? Of course, there will be new technologies-vaccines, architectural advances, and redesigned spatial configurations to minimize and perhaps even eliminate the threat of the coronavirus - but what about adaptive refinements in our moral capacities and practices? For that matter, what do we even mean when we talk about our moral capacities? Human evolutionary hardiness attributed to the human brain is not simply about rational intelligence; our moral capacities may be a singularly defining trait deserving a fair share of credit for fueling human adaptive learning and thrival. What if we choose to respond to adaptive moral challenge of the coronavirus by building a more lifegiving path for our future?

At some point in our history-or more probably, an extended period of pivot points-we moved beyond instinct to conscious, reflective consideration of our behavioral options in any given moment. As we were developing this abstractive capacity to imagine alternative future scenarios of actions and consequences, our communicative capacities extended far beyond contented grunts and alarmed facial expressions to an immensely expressive vocabulary of desires, fears, and plans that enhanced our relational capacities of attachment and collective identity. Over the past couple hundred years - the blink of an eye in evolutionary time-we progressed quickly towards a new pivot point in our history, having focused our collective intelligence on building a world we can no longer live in: A contaminated, collapsing biosphere of dying species, intolerable climate, toxic air and water, disrupted economies, resource scarcities, regime failures, and technology-driven and capitaldependent material and social infrastructures that leave billions of overwhelmed people unable to provide even the most basic necessities for themselves and their families. And now another pandemic with promises of more to come when global travel bounces back to ensure the quick, lethal spread of another virus.

The coronavirus pandemic is a wake-up call—devastating, certainly-but a deadly threat is hardly a novel phenomenon in human evolutionary history. What is new is our arrival at-or perhaps more accurately, our creation of - the Anthropocene, a much-debated evolutionary point in geohistory when the impact of human activities on the Earth has begun to outcompete natural processes (Crutzen 
2006). The Anthropocene imposes new, unprecedented moral challenges that most of humanity's wisdom traditions were not designed to even contemplate, much less resolve (Jenkins 2013). The current pandemic is the latest point in humanity's moral evolution of adaptive response to moments of urgent threat that have tested, expanded, and defined our character and moral capacities as a species. Rather than falter under the moral burden of the coronavirus threat and its consequences, we can lean into the challenge as an opportunity to refine our moral understanding and expand our moral capacities to take on even greater challenges that threaten the future of humanity and the planet. This is an opportunity to stretch our moral horizons by taking responsibility for the urgent moral challenges we have created-perhaps unwittingly - and inventing new ethical frameworks and tools that will lead us to new moral understandings and solutions to the moral challenges we face.

Uncertainty is a fact of life and humans-like most creatures-are wired to respond with heuristic tools that for the most part serve them well (Gigerenzer 2014). Uncertainty escalating to risk or danger triggers a distinctive response of heightened alertness and cognitive decision-making processes that for humans creates a sense of moral urgency involving a moral calculus of vulnerability and responsibility for potential actions and consequences. As a complex amalgam of individuated and socialized capabilities, most humans rely on a moral brain that functions seamlessly most of the time, but moral urgency can weigh heavily on people faced with moral demands that far exceed their capacities and it is normal for conscientious people to experience moral distress when they fail to uphold their own values. The coronavirus pandemic has introduced millions of people to experiences of moral distress usually encountered only in high-risk jobs-emergency and intensive care clinicians, first responders, police officers, fire fighters, and combatants-who suffer guilt and despair when they are unable to fulfill duties of care for the wellbeing of others (Rushton 2018).

Moral distress looms in the pandemic-induced debate over protecting lives versus protecting livelihoods, exposing and illuminating deep fissures in the fabric of the global social order. We dread reckoning with moral failure but don't know how to avoid it. How is it that the toll of COVID-19 morbidity and mortality weighs far more heavily on already disadvantaged people and communities? Why were governments in wealthy nations so ill prepared to protect their citizens from a threat that had been predicted by public health officials for years? Why did it take a pandemic to notice that local business ecosystems crippled by globalization were powerless to produce needed goods for their communities? How can people who feel betrayed by their leaders and institutions regain trust in government, business, and the economy? Will we ever feel safe again?

As nations and cities struggle with decisions to reopen businesses and markets, moral distress will take on a more urgent tone in the dilemmas or individuals, families, and communities who fear their inability to fulfill their immediate moral obligations:

- How can I return to work if my baby's daycare is closed?

- How can I send my child to school and protect her from the coronavirus?

- Should I quit my job to take care of my family? 
- How can we let Grandpa suffer and die alone in the hospital?

- How can we keep our employees are safe?

- Should we pay our furloughed employees or pay our rent?

- How do we prepare for the next pandemic wave?

- Can we afford to retire with devalued portfolios?

- Should I close my business or try to rebuild it?

Caught up in the urgency of moral distress, we are acutely aware of how vulnerable we are as individuals, families, and communities to catastrophes of disease, economic ruin, and suffering. Our vulnerability is exacerbated by failure to provide protection and care; guilt and anxiety over moral failure can undermine our sense of moral agency, integrity, self-confidence, and hope for the future. Unable to muster up the moral courage to hope, some of us are sucked into downward swirling vortex of nihilist despair. As painful as it is, however, these untenable situations of moral adversity invite resilience; rather than succumb to moral failure, we can absorb, utilize, and even grow from it by developing new skills and strategies in responding to moral distress and the conditions of moral urgency (Rushton 2018). For those of us who are able to see the moral imperative of hope in the face of disaster, we can and must find better ways to live.

Margaret Walker defines morality as practices of responsibility with special attention to the collective obligations that vulnerability places on the strong, the privileged, and society as a whole. (Walker 2007). If the coronavirus teaches us anything, it is how much we as humans need to lean into our responsibility for the vulnerable people among us and for the Earth that is our home. Leaning into the moral challenge of responding and adapting to the coronavirus, we have the opportunity to build a world of business, government, and social practices that align more closely with values of care, justice, and fairness that we espouse as a modern community of nations (United Nations 1948). We can hold ourselves and our institutions accountable for practicing these values, acknowledging our wrongdoings, and making things right when we fail. As modern humans, we have done many things right, but the coronavirus has illuminated our failures of justice and care for the vulnerable people and places among us. We can do better.

\section{Compliance with ethical standards}

Conflict of interest As the sole author, I declare that I have no conflict of interest in writing or publication of this manuscript.

\section{References}

Crutzen PJ (2006) The "anthropocene". In: Ehlers E, Krafft T (eds) Earth system science in the anthropocene. Springer, Heidelberg, Berlin, pp 13-18

Gigerenzer G (2014) Risk savvy: how to make good decisions. Viking, New York

Glaeser E (2011) Triumph of the City: how our greatest invention makes us richer, smarter, greener, healthier, and happier. Penguin Group, New York 
Glaeser E (2020) Citties and pandemics: a long history. The Manhattan Institute, New York

Jenkins W (2013) The future of ethics: sustainability, social justice, and religious creativity. Georgetown University Press, Washington

Rushton CH (2018) Moral resilience: transforming moral suffering in healthcare. Oxford University Press, New York

Singer P (2004) One world: the ethics of globalization, 2nd edn. Yale University Press, New Haven

United Nations. General Assembly (1949) Universal declaration of human rights, vol 3381. Department of State, New York

Walker MU (2007) Moral understandings: a feminist study in ethics. Oxford University Press, New York

Publisher's Note Springer Nature remains neutral with regard to jurisdictional claims in published maps and institutional affiliations. 